\title{
Minicurso: OBJETOS DE APRENDIZAGEM E SCORM
}

\section{Autores:}

\section{Marie-Christine Julie Mascarenhas Fabre}

Doutoranda em Informática na Educação (PGIE/UFRGS) e Especialista em Informática na Educação com experiência no projeto e desenvolvimento de cursos e objetos de aprendizagem para educação a distância.

\section{Renato Luís de Souza Dutra}

Doutorando em Informática na Educação (PGIE/UFRGS) e Mestre em Ciência da Computação com conhecimentos e desenvolvimento de sistemas e sites interativos.

Súmula: Apresentar os conceitos relacionados ao projeto, desenvolvimento e empacotamento de objetos de aprendizagem em conformidade com o padrão SCORM (Sharable Content Object Reference Model) e ferramentas para criação e empacotamento de objetos nesse padrão.

\section{Tópicos:}

- Objetos de aprendizagem

- Padrão SCORM

- Histórico e objetivos da ADL

- Conjunto de especificações SCORM 1.2

- Desenvolvimento de conteúdos educacionais SCORM

- Sharable Content Objects (SCO's) e Course Assets

- Empacotamento de conteúdo (Content Packaging)

- Ambiente de execução (Run-Time environment)

- Teste de conformidade SCORM

- Instalação do ADL Suite Test

- Teste de Assets, SCOs e Pacotes

- Ferramentas para criação e empacotamento de objetos no padrão SCORM

\section{Metodologia:}

A metodologia do curso será teórico-prática, com apresentação dos conceitos e ferramentas relacionados e desenvolvimento de objetos de aprendizagem. 